\title{
As Inadequações do Sistema Tradicional de Custos em um Novo Ambiente de Fabricação
}

\section{Edson de Oliveira Pamplona}

Professor do Departamento de Produção

Escola Federal de Engenharia de Itajubá

Av BPS, 1303 - Caixa Postal 50

$375(0)(0)(0)()$ - Itajubá-MG

Palavras chaves: Contabilidade de Custos, Controle de Custos, Análise de Performance Key words: Cost Accouting, Cost Management, Performance Evoluation

\section{RESUMO}

Esle trabalho apresenta os principais problemas relativos a ampla utilização de Sistemas de Custos tradicionais em um ambiente de produção que se caracteriza pela inovação na adoção de novas feconologials. tanto em nível geral como TQC. IIT: CIN - quanto em niveis especilicos-tais como CAD, CAl: C.APP. MRP. MRPII, SPC. CNC. Roboblica e FMS. Demonstra-se, portanto, a necessidade de Sistemas de Cuslos cue alendam adeyuadamente suas funções. con participação efetiva na busca pela excelência gerencial das empresas.

\section{ABSTRACT}

This work presens the main problems related wo the use of traditional coss systems in a production enviromment

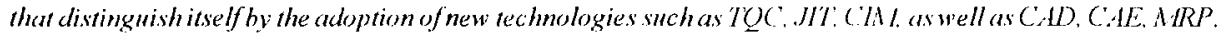
MIRPII. SPC. CNC, Robotics and $\mathrm{A} \mathrm{S}$, in especific terms.

It is also demonstrated the need of adequating cost systems to its functions. In this way this updated Cost System suppliex an effective contribution wo the search for the company smangememexcellence. 


\section{Introdução}

A Contabilidade de Custos atualmente utilizada pelas empresas está estruturada em conceitos descnvolvidos há quase um século, quando a natureza da competição c as demandas por informações internas cram muito diferentes das existentes atualmente.

São três as funções básicas dos sistemas de custos:

- A avaliação de estoques para elaboração de demonstrações fiscais e financeiras;

- O controle operacional que fornece o "feedback" aos administradores de produção c aos gerentes de departamentos sobre os recursos consumidos nas operações;

- As medidas de custos de produtos individuais usadas para apreçamento e avaliações de margens de lucros.

Entretanto, o sistema de custos tradicional não atende adequadamentc as funções citadas acima e se direciona principalmente para a função de avaliação de estoques para elaboração de demonstrações financeiras, buscando suprir, precariamente, a necessidade de informações dos diversos agentes interessados na situação da empresa como, por exemplo, os acionistas, fornecedores, clientes, governo e a própria administração da empresa.

Dessa forma, as funções deControle Operacional, que necessita de informação com alta freqüencia e elevado grau de objetividade, e de Medida do Custo do Produto, que demanda cxtenso grau de apropriação de todas as atividades da empresa ao nível de produtos individuais, são bastante prejudicadas.
Johnson e Kaplan (1987), no livro Relevance Lost, documentam a subversão dos sistemas de Contabilidade Gerencial, cuja proposta original era a de fornecer informações para facilitar o Controle de Custos e para medidas de performance em organizações hierárquicas e, com o tempo, foi transformada na compilação de custos para atender demonstrações financeiras periódicas.

A mentalidade de contabilidade financeira citada acima, o capital intensivo nos processos de produção com redução constante da participação de Mão-de-obra direta nos produtos finais e os novos conceitos em tecnologia de produção são os principais responsávcis pela inadequação dos sistemas de custos tradicionais aos processos produtivos de hoje.

\section{O Sistema Tradicional de Custos}

O sistema tradicional de custos tem como característica a utilização de um método de apropriação de custos em dois estágios:

- no primeiro estágio os custos são imputados aos centros de custos - unidade mínima de acumulação de custos - através de várias bases de apropriação como, por exemplo, quantidade produzida, horas de mão-de-obra direta, valor de mão-de obra direta, área ocupada, valor da produção, potência das máquinas, etc;

- cm um segundo estágio os custos são apropriados dos centros de custos aos produtos através de uma base de volume, quase sempre horas de mão-de-obra direta.

Outra característica importante dos sistemas tradicionais é a consideração de que os 
custos fixos permanecem inalterados com a alteração no volume de produção e que custos semifixos - ou semivariáveis - podem variar em degraus de acordo com o nivel de atividade.

\section{O Problema da}

\section{Apropriação baseada em Mão-de-Obra Direta}

Miller e Vollmann (1985) apresentam um gráfico (figura 1) que mostra o crescimento dos custos indiretos como uma proporção do valor agregado, enquanto que a mão-de obra direta caiu consistentemente ao longo dos últimos 100 anos.

Os custos indiretos cresceram com a elevação da depreciação e das atividades de apoio relacionadas à manutenção $\mathrm{e}$ à operação de equipamentos cada vez mais automatizados $\mathrm{e}$ a sua distribuição aos produtos continua a ser efetuada com base na mão-de-obra direta que tem uma participação cada vez menor.

Assim, os custos dos produtos estão sendo calculados de forma incorreta, pois a base de apropriação é proporcionalmente baixa e normalmente não é aquela que realmente conduz. os custos indiretos, ou seja, apresenta baixa correlação com estes custos. Desta forma, pode-se encontrar taxas de absorção - que relacionam os custos indirctos à utilização de determinada base de apropriação - superiores a $1000 \%$ sobre a base mão-de-obra direta quando, na realidade, grande parte dos custos variam com a diversidade e complexidade dos produtos.

Além disso, com a flexibilidade atual, a mão-de-obra trabalha com vários produtos ao mesmo tempo, sendo praticamente impossível apropriar adequadamente as horas de mãode-obra direta aos produtos. tornando-a ainda menos confiável como base de apropriação.

As distorções são muitas e as informações geradas podem levar a decisões crrôneas. $O$ custo dos produtos provenientes de linhas com mão-de-obra intensiva é sobrecarregado com os custos indiretos originados pelas linhas altamente automatizadas, fazendo com que tais produtos pareçam não lucrativos.

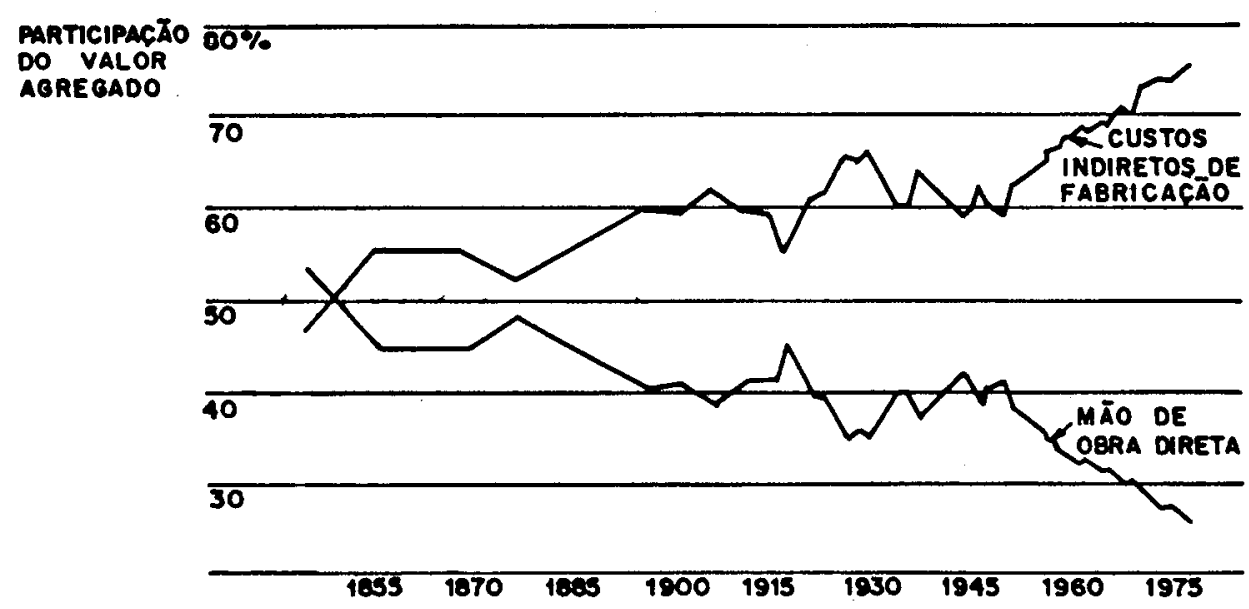

Figura 1 - Componentes do valor agregado

Fonte: MILLER e VOLLMANN (1985) 
Assim. linhas de produtos podem ser abandonadas ou atć fábricas inteiras podem ser desativadas cm função de informações incorretas fornecidas pela contabilidade sobre os custos do processo produtivo.

A apropriação de custos indirctos com basc na mão-de-obra direta ć classificada por Schemenner como um dos "buracos negros" da contabilidade de custos, pois um gerente de linha de produçào pode fazer sua opcração parccer melhor, no mínimo a curto prazo, se cle reduzir a Mão-de-obra direta. Agindo assim cle recebc um benefício duplo: o custo da Mào-de-obra direta por si só ć reduzido e o custo indircto apropriado para sua operação ć menor. O problema surge naquelas situações onde a adição de Mào-de-obra direta ć a única forma de remediar um gargalo ou de melhorar um processo.

Hiromoto (1988) observou que, apesar das cmpresas japonesas concordarem que deveria cxistir uma relação lógica c causal cntre a carga de custos indirctos $\mathrm{c}$ a apropriação de custos cm produtos individuais. muitas companhias continuam apropriando custos indiretos com basc $\mathrm{cm}$ mão-de-obra dircta. pois cria-se o forte c descjado incentivo pró-automação por toda a organizaçào.

Não há como discordar. se a meta de um sistema de custos fossc apenas a automatização. entrctanto, para que as diversas funções de um sistcma de custos scjam adcquadamentc atendidas. "as bases de apropriação devem ser capazes de contabilizar todos os aspectos da diversidade c complexidade do produto".

\section{Os Custos Fixos são Realmente Fixos?}

Scgundo Johnson c Kaplan (1987), o fato de muitos dos mais cxpressivos custos de produtos serem chamados de fixos ou "afundados", revela a "pobreza de pensamento da contabilidade de custos corrente". Todos os custos são conscquência de decisões gerenciais c o fato de algumas categorias de custos não variarem a curto prazo, de acordo com a produção, não signifíca que clas não scjam controláveis.

De fato, a referência para a classificação de custos como fixos tem sido o volume dc produção $\mathrm{cm}$ um cenário de curto prazo, mas, novamente. a base volume pode criar desinformaçõcs.

Conforme visto anteriormente, os "custos fixos" vêm se alterando ao longo de várias décadas. aumentando cada vez mais sua participação no custo de fabricação, e a sua apropriação inadequada não mostra o fato gerador destes custos, tornando impossivel sua identificação para fins de controle. eventual rcdução. ou mesmo eliminação.

Os sistcmas de custos tradicionais "escondem “ os custos de departamentos típicos de custos indirctos por apropriar tais valores usando como base a Mão-de-Obra ou Materiais. $\mathrm{O}$ uso de bases de apropriação relacionadas ao volume encobrem que o principal determinante da variação dos custos destes departamentos de apoio é o grau de complexidade da cstrutura de produção c não simplesmente o volume produzido

\section{Outros Efeitos Prejudiciais}

O sistema corrente de custos afeta dirctamentc as atividades de controle de custos. análise de desempenho. e de análise de investimentos. 
Por ser uma atividade com necessidade de informaçòcs a curtissimo prazo. o controle de custos deve se utilizar da tecnologia computacional atualmente disponivel para coletar dados c produzir relatórios de forma instantânca. mas. apesar de muito ter sido realizado na integração entre dados da produção $c$ da contabilidadc. os bencfícios são poucos c são apenas a ponta do "iccberg".

Entretanto, de nada adianta rapidcz nas informações sc clas não forem corretas.

Dc acordocom Kecgan, Eilcre Jones (1987) as medidas de performance não necessariamente têm de scr cxpressas como custo, mas o custo ć a base mais importantc para a medida de performance. No entanto, conforme os autores acima. "ninguém que estuda com sericdade os sistemas de administração de custos de companhias industriais os consideram adequados $"$.

As medidas tradicionais de performance. como a ROI (rctorno sobre o investimento), podem ser contraprodutivas, pois modificam o comportamento dos avaliados de tal forma que lcram ao acréscimo nos cstoques, ao aumento de niveis de complexidade e aos problemas de qualidade.

As atividades de análise de performance. de análise de investimentos e de mensurafão do custo da qualidade, necessitam de informaçòcs que o sistema de custos tradicional de custos nào fornece. As medidas quantitativas financeiras nccessárias são difíceis, ou mesmo impossivcis de serem detalhadas. enquanto que as medidas quantitativas não financciras normalmente nào são fornccidas pela atual Contabilidade Gerencial.

Tais atividades necossitam. alćm disso. de medidas qualitativas para que se possa decidir com scgurança

\section{Conclusões}

A prcocupação principal $\mathrm{cm}$ obtcr informações de custos para alimentar relatórios financeiros e a clcvação constante de capital intensivo $\mathrm{cm}$ fábricas cada vez mais automatizadas com conscqüente diminuiçào da proporção de mão-de-obra dircta podem ser consideradas as principais causas da obsolescência dos sistemas de custos tradicionais.

As diversas funções de um sistema de custos não estão sendo atendidas adequadamente c. o que é pior, as decisões estão sendo tomadas com base em informações totalmente incorrctas.

Enquanto que a busca pela climinação de desperdicios. objeto de filosofias produtivas como "Just-in-Timc" prevaleccm, a contabilidade de custos atual destina esforços para a avaliação de estoques.

É fundamental que os sistemas de custos sc direcionem. não só para o auxilio, mas para a participação ativa, compondo o leque de ferramentas utilizadas pelas cmpresas que pretendem ser competitivas

Para tanto. o pessoal cnvolvido com o projeto. a implantação. a cxccução c o controle de sistemas de custos. deve conhecer. com detalhes. de que forma surgem os custos c para que serão utilizadas as informaçōes geradas. Isto só é possivel se tais clementos cntenderem profundamentc os processos de fabricaçào.

Merece destaque o surgimento do sistema de custos bascado $\mathrm{cm}$ atividades - o ABC (Activity-Based Costing) - que se distingue pela velocidade com que passou da teoria para a prática. com implantação $\mathrm{cm}$ diversas $\mathrm{cm}$ presas de porte no mundo inteiro. O Sistema 
$\mathrm{ABC}$ é visto como uma ferramenta para a cstratégia empresarial.

Justifica-se o custcio baseado em atividades, pois são elas que consomem os recursos e devem ser consideradas custos dos produtos.

A identificação dos custos das atividades que não adicionam valor a um produto é fator importante no processo de melhoria contínua, sendo, portanto, uma característica necessária de um sistema de custos adequado.

O prazo para que as empresas continuem suportando os problemas gerados pela utilização do sistema tradicional de custos em um novo ambiente de fabricação está terminando.

\section{Referências Bibliográficas}

COOPER, Robin, KAPLAN, Robert S. How Cost Accounting Distort Product Costs. Management Accronting. Apr., 1988

DILTS, David, GRABSK, Severin V. Advanced Manufacturing Technologies: What They Can Offer Management Accountants. Management Accounting. Feb., 1990

HIROMOTO, Toshiro. Another Hidden Edge - Japanese Management Accounting. Harvard Business Review. July/Aug., 1988

HOPP, João Carlos, LEITE, Hélio de Paula. O Crepúsculo do Lucro Contábil. Revista de Administração de Empresas. Out./Dez., 1988
JOHNSON, H. Thomas, KAPLAN, Robert S. Relevance Lost. Boston: Harvard Business School Press, 1987

KAPLAN, Robert S. Yesterday Accounting Undermines Production. Harvard Business Review, July/Aug., 1984

KAPLAN, Robert S. One Cost System isn't Enough. Harvard Business Review. Jan./ Feb. , 1988

KEEGAN, D., EILER, R. G.. JONES, C. R. Are Your Performancc Measures Obsolete? Management Accounting. June, 1987

MILLER, Jefrey G., VOLLMANN, Thomas E. The Hidden Factory. Harvard Business Review. Sept./Oct., 1985

OSTRENGA, Michacl R. Activities: The Focal Point of Total Cost Management. Management Accounting. Feb., 1990

SCHEMENNER, Roger W. Escaping of Black Holes of Cost Accounting. Business Horizons. Jan./Fev., 1988 